\title{
Movement of People on Stairs during Fire Evacuation Drill-Japanese Experience in a Highrise Office Building
}

\author{
MASAHIRO KAGAWA, SATOSHI KOSE, and YASABURO MORISHITA \\ Building Research Institute
}

Oho, Tsukuba, Ibaraki 305 Japan

ABSTRACT

Behaviour of people during a simulated fire evacuation practice in a highrise office building in Tokyo was observed through video recording: subjective evaluation by the evacuees was also collected. About a fifth of the residents present in the building evacuated through two emergency stairs to the ground. The result suggests that stagnation of flow within the stairwell was noted in several spots even at this small number of evacuees. It was pointed out that doors opening into the stairway obstructed the smooth flow of people in the stairwell. Simultaneous total evacuation seems impractical in highrise buildings; reasonable procedures for selective evacuation need to be developed. It is also concluded that more frequent education on fire safety is necessary for the building users to get accustomed to the evacuation procedures and facilities.

KEYWORDS: Emergency stairs, evacuation, fire safety, highrise building, human behaviour, office building, questionnaire, video recording.

\section{INTRODUCTION}

Modern buildings are not completely safe from risks of fire or other disasters in spite of multiple technical measures provided. It is supposed to be the best way of assuring safety for the residents to evacuate from the building to the ground. It is not a common practice in Japan, however, to conduct such a fire drill without prior notice. Yet, not a small number of office buildings practice a scheduled evacuation on the occasion of "Disaster Prevention Day: September the 1st". The authors had the chance of making video recording of an evacuation practice in a highrise of fice building. A questionnaire survey was also done to examine subjective evaluation by the evacuees to the practice and their attitude to the fire risk in the building. The result of the study and the implication arising from this is discussed.

\section{DETAIL OF THE EVACUATION PRACTICE}

The highrise office building where this observation was conducted is in the Shinjuku Metropolitan Area in Tokyo. It has 53 stories and 5 basement stories: Floors between the 6 th and the 28 th are used by the owner, and the remaining

Masahiro Kagawa was a visiting researcher from April 1984 for one year. Address all correspondence to Taisei Corporation, Shinjuku, Tokyo 160-91, Japan. 
floors are let to a lot of smaller tenants. Shops and restaurants are in two basement stories and also on the 53rd story. The typical floor plan of the building is in FIG.1.

The evacuation practice was conducted on Tuesday the 4th September 1984 (because the 1st was Saturday), and it was estimated that about 1,500 persons, a fifth of the residents present in the building, participated in the practice. It has been notified in advance that an evacuation practice is to be started at about 14:30. It has been supposed that following to a large earthquake, fires will break out at several floors in the building, and an order of total evacuation will be announced: Then, evacuees from each floor are guided by their group leaders to the emergency stairs, and they are to climb down the stairs.

The lobbies for access to the two emergency stairs are designed large enough to temporarily hold all residents of that floor protected from smoke and fire. The purpose of the observation is, therefore, to reveal the flow condition of the evacuees in the stairwell, and especially to reveal the mixing condition of the evacuees from different floors at the entrance door to the stairwell. To fully accomplish the aim of the study, four paired video cameras were set up in and out of entrance doors to the stairwell. Two sets were equipped with two cameras and a camera wiper, and the visual data were conbined directly into one video frame. Several other cameras were used to monitor the general flow of people during evacuation. One of them was placed on the first floor to record the final outflow of the evacuees from the stairwell. The positions of the cameras are identified in FIGS.2 and 3 . Although the building had two main emergency stairwells, both of which were used this time, only the east one was selected as the object of observation. It was unavoidable due to shortage of equipments and staff. To compensate for this drawback, and also to try to simulate condition of congestion during total evacuation, the evacuees of successive floors between the $25 \mathrm{th}$ and the $28 \mathrm{th}$ where the cameras were mainly situated were to use the east stairwell as the emergency stair. Originally, the evacuees from two consecutive floors were supposed to use east and west stairwells alternately during the practice.

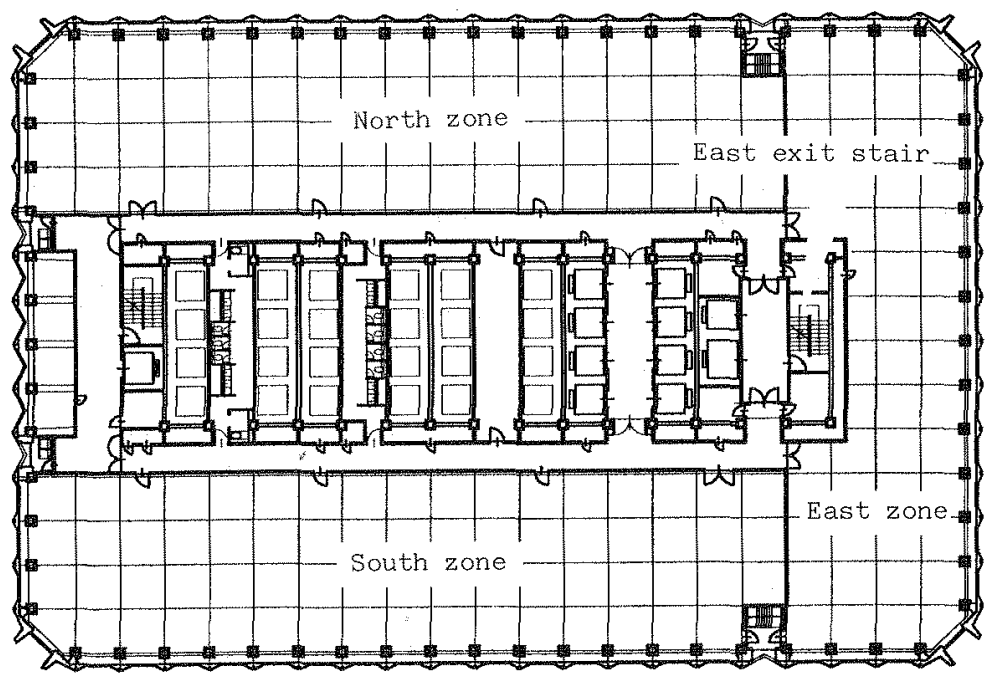

FIGURE 1. Typical floor plan of the building. 


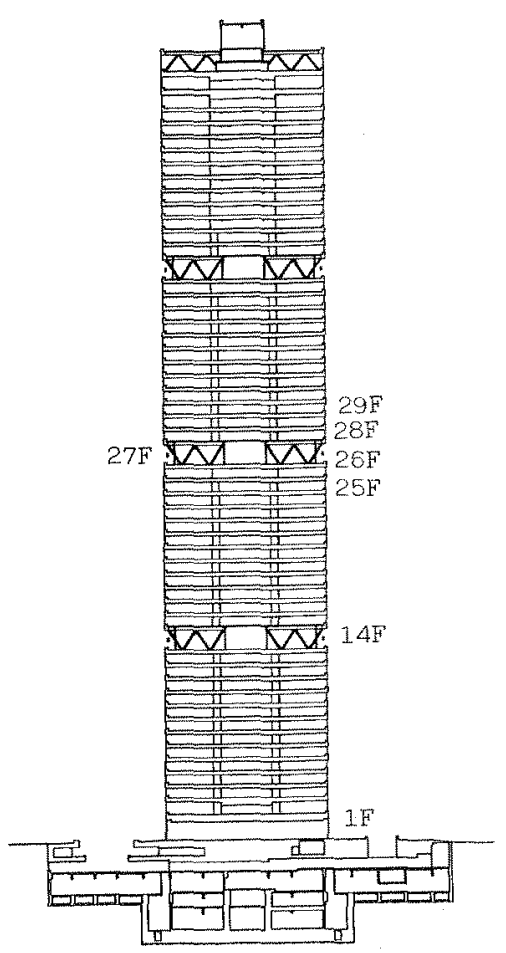

FIGURE 2. Section of the building.

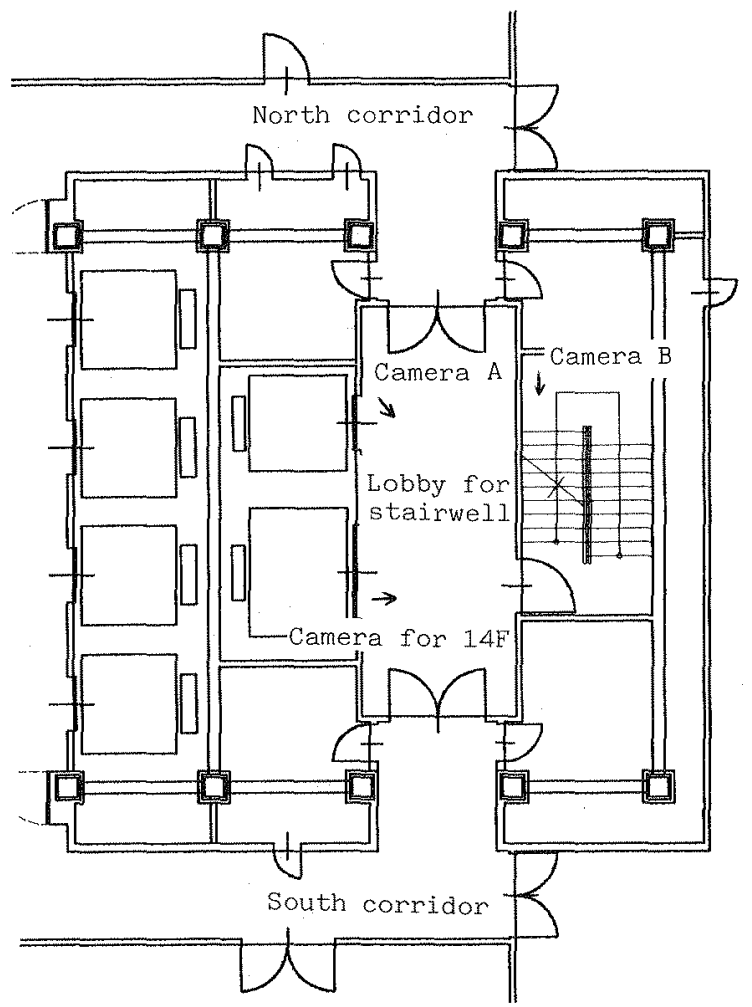

FIGURE 3. Detailed plan of lobby for east emergency stairwell.

In addition to these cameras, two observation staff walked down the stair both with a video camera, thus directly recording the conditions in the stairwell, and four other staff walked down the stair with evacuees, all with a portable tape recorder, just the same way as Pauls and Jones(1) did in 1972. They were all instructed to start climbing down with the last evacuee of the floor, and were to report noteworthy findings during their traverse.

The questionnaire survey was aimed at obtaining the attitude of the evacuees to the evacuation practice: Evaluation of the procedure of practice, subjective response to the evacuation condition, and their characteristic data were collected. The usual practice of stair use was also asked. To facilitate the comparison of data with those of Pauls (private communication), the questionnaire form was kept identical where possible. Taking into consideration of the possibility of good response rate to the questionnaire, the questionnaire sheets were distributed only to those who participated in the practice and who belonged to the owner-tenant company ( $T$ Corporation) and to a medium sized corporation (YEW Company) that rented three stories between the 48th and the 50th. These two organizations are supposed to be the best kind of tenants/residents in the building; other tenants are suspected to have less keen interest to the life safety in case of emergency. The number of expected participants and the stairwell selection for $\mathrm{T}$ Corporation and YEW Company are listed in TABLE 1 . For other participants, no detailed information was available. 
TABLE 1. Number of expected participants in the evacuation.

\begin{tabular}{crrrrrrrrrrrrrr}
\hline Story & 6 & 7 & 8 & 9 & 10 & 11 & 12 & 13 & 15 & 16 & 17 & 18 & 19 \\
\hline Total & 10 & 16 & 50 & 50 & 50 & 50 & 30 & 50 & 50 & 50 & 10 & 10 & 45 \\
Male & 5 & 9 & 30 & 30 & 40 & 35 & 20 & 35 & 35 & 45 & 5 & 5 & 35 \\
Female & 5 & 7 & 20 & 20 & 10 & 15 & 10 & 15 & 15 & 5 & 5 & 5 & 10 \\
\hline Stairwell & $W$ & $E$ & $W$ & $E$ & $W$ & $E$ & $W$ & $E$ & $E$ & $W$ & $W$ & $W$ & $W$ \\
\hline & & & & & & & & & & & & \\
\hline Story & 20 & 21 & 22 & 23 & 24 & 25 & 26 & 28 & Subtotal & $48 / 50$ & Total \\
\hline Total & 45 & 65 & 45 & 25 & 4 & 70 & 40 & 70 & 835 & 70 & 905 \\
Male & 35 & 50 & 35 & 20 & 2 & 55 & 25 & 55 & 606 & NA & \\
Female & 10 & 15 & 10 & 5 & 2 & 15 & 15 & 15 & 229 & NA & \\
\hline Stairwell & $E$ & $W$ & $E$ & $W$ & $W$ & $E$ & $E$ & $E$ & $* *$ & NA &
\end{tabular}

* Number of people to use east stairwell between the 6 th floor and the 28 th floor is 486 , and those to use west one is 349 .

RESULTS

Observation of People's Movement

The first public announcement stating that a large earthquake occurred was released at $14 \mathrm{~h} 24 \mathrm{~m} 35 \mathrm{~s}$, and the second one reporting the simulated outbreak of fires at the $3 \mathrm{rd}$, the $29 \mathrm{th}$, and the $43 \mathrm{rd}$ stories was done at $14 \mathrm{~h} 29 \mathrm{m02s}$. This second announcement urged all the residents to evacuate through emergency stairs without delay. The first evacuees (perhaps from the 3rd floor) came out of the exit door of the stairwell to the first floor lobby at $14 \mathrm{~h} 29 \mathrm{~m} 44 \mathrm{~s}$, just 42 seconds after the announcement started, and others followed. It took about 16 minutes for almost all the evacuees to come down to the ground. The flow of evacuating people came out in groups headed by their leaders. The positions of the observer-staff with time are plotted in FIG.4. The total number of evacuees that came out of the ground floor stair exit is given in FIG.5. Flow rate out of the stair is also plotted.

Result of Questionnaire Survey

Seven hundred sixty-seven questionnaire sheets were collected out of 905 sheets that were delivered through group leaders. Fifty-five persons that responded to the questionnaire work for YEW Company, and the rest work for $T$ Corporation. The age/sex distribution in TABLE 2 suggests that females over the age of 35 are comparatively rare among the samples, while females dominate under 25 years of age. It seems that younger people are a little over-represented in the sample. As to their subjective evaluation of the ability to descend long stairs, there is a tendency. that older people report smaller number of stories for their maximum ability. Nearly sixty percent of subjects estimate that they can descend over 20 stories, but only just 30 percent of people actually have the experience of climbing down such a long distance. Their most popular use of stairs is going a couple of stories up and down. They use stairs instead of elevators mostly because elevators are crowded or going by stairs are faster. But about $14 \%$ of people rarely or never use stairs during usual time. 


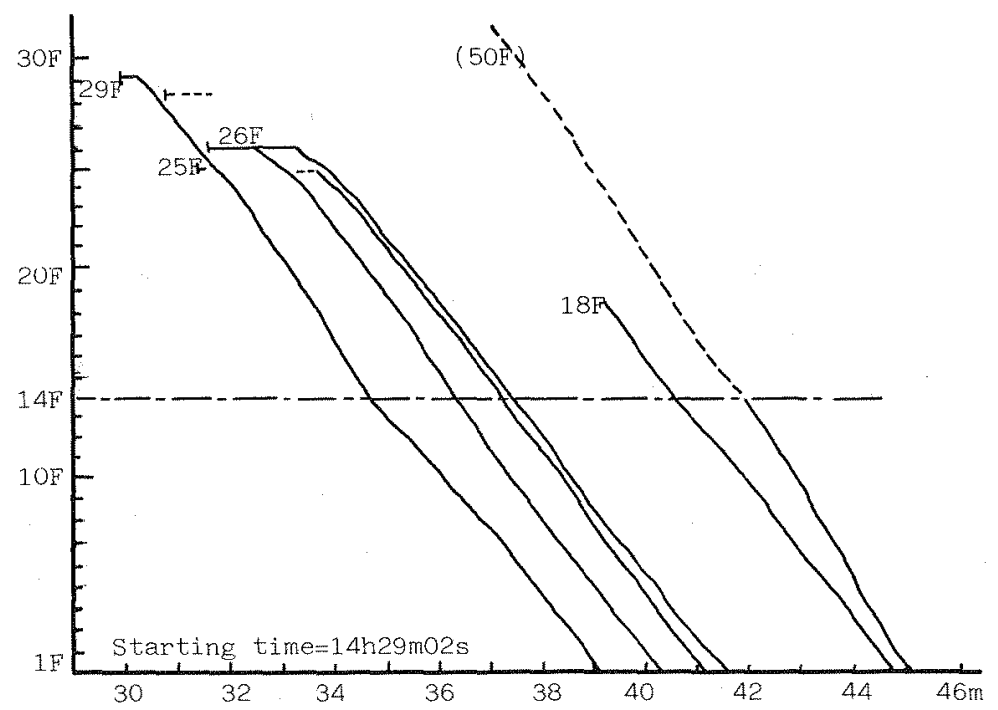

FIGURE 4. Movement of observers with evacuees in the east emergency stair.
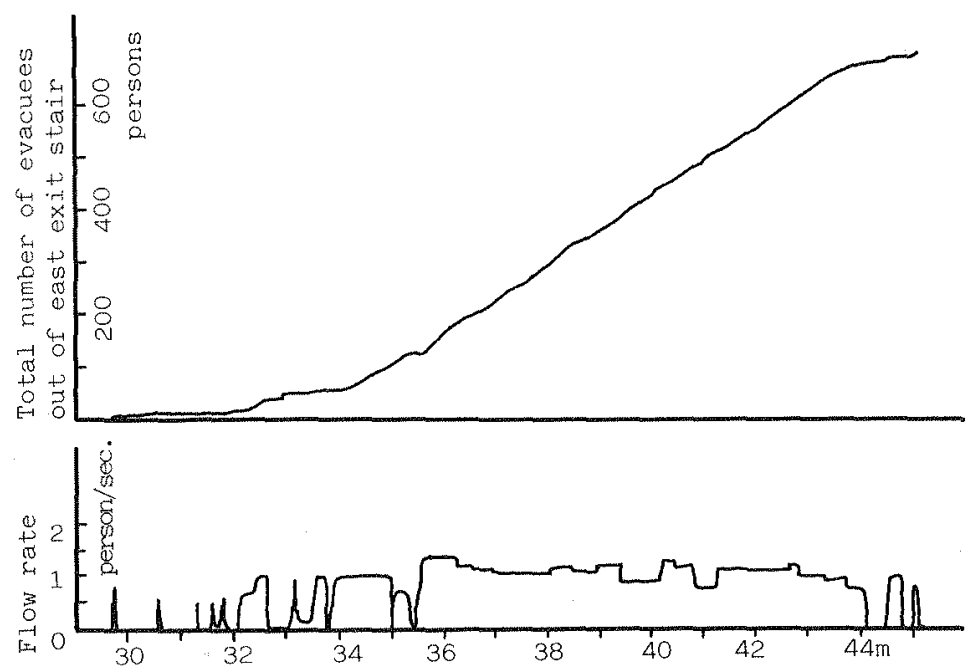

FIGURE 5. Number of evacuees out of east emergency stair, and flow rate of people out of stairwell at the first floor.

TABLE 2. Age-sex distribution of evacuees that answered questionnaire.

\begin{tabular}{rrrrrrrr}
\hline Sex & Age & $15-24$ & $25-29$ & $30-34$ & $35-54$ & $55-$ & Total \\
\cline { 5 - 8 } Male & 65 & 86 & 99 & 259 & 17 & 526 \\
Female & 126 & 62 & 16 & 17 & 1 & 222 \\
\hline Total & 191 & 148 & 115 & 276 & 18 & $748 *$ \\
\hline
\end{tabular}

* In addition to this, there are 19 subjects with age or sex unknown. 
From the response of the subjects to the stair condition during evacuation practice, it is clear that the practice went without serious trouble. This was expected because only about a fifth of the residents in the building participated in the evacuation. From the answer to the questionnaire, however, it is evident that there were cases of stagnation of people's flow in the stairwell. About $30 \%$ of subjects stated the occurrence of slowing down or stopping of people's flow during the evacuation practice. Those subjects that started descending from the 15th floor, the 18th (not observed because they used west emergency stair), the 20th, the 22nd, the 23rd (not observed either), the 25th, the 26th, the 28th and the 50th claimed the effect of stagnation. About two thiras of the subjects reported that the speed of descent was somewhat slower for them when it was slowest. The blockade by people coming from upper floors was significantly claimed by the residents of the 13 th, the 16th, the 25 th and the $26 \mathrm{th}$. On the other hand, residents that started from the 15 th, the 18th, the 22nd and the 49 th complained the disturbance in the stairwell by the people coming into. Some complained this because of the narrowness of the emergency stairs, which is just $1200 \mathrm{~mm}$ wide. This is the minimum stair width requirement for large office buildings in Japan, and this width originally assumed two files flow of evacuating people according to the regulations, as Pauls(3) discussed. However, from the result of the flow observation, there was only one evacuee on every step of the stair, using left and right side of the step alternately (staggered files), or two persons on the same step and the succeeding persons on the next but one step just as shown in FIG.6, thus resulting density on the stair was 1 person per step in either case (this density is around 3 persons per square metre). Higher density was rarely observed even during stagnation of people's flow. It was natural because this evacuation was an exercise notified in advance, and practically no psychological stress was felt by the evacuees.

Judging from the traverse of observer-evacuees in FIG. 3, the average speed of descent was found to be around 16 seconds for a standard floor height of 3650 $\mathrm{mm}$, without noticeable disturbance in the stairwell. This is close to the speed of climbing down during unobstructed stair use as Kose et al.(4) reported. For some cases, however, it took 20 seconds or more to descend one story, indicating
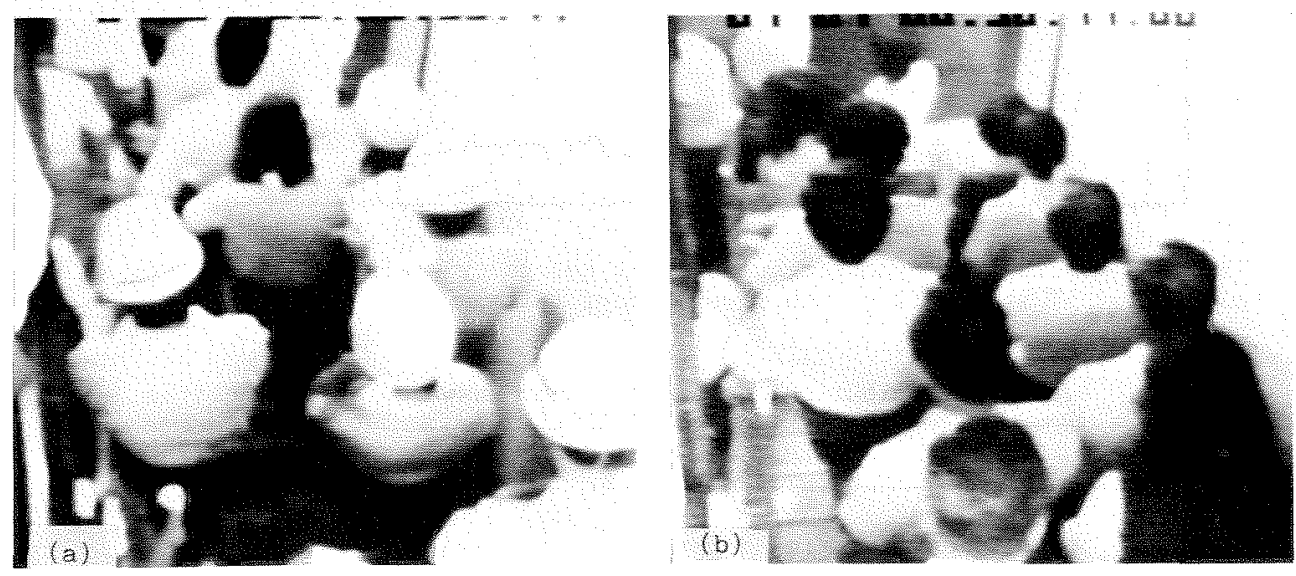

FIGURE 6. Arrangement of people on the flight during maximum flow on the 25th floor. Left figure (a) at time $14 \mathrm{~h} 33 \mathrm{ml} 6 \mathrm{~s}$, and right one (b) at 14h34m00s. 
the effect of congestion in the stairwell. It occurred at several stories at different times. On the 25th floor, the front of people coming into met with the front of people descending just on the landing, and people coming down from upstairs waited on the upper flights to let evacuees of the 25 th floor to come in, for a short period. In other floors where the door was initially closed, however, it was difficult for the evacuees to come into the stairwell because the door had to be opened against the flow of people on the flights and landings. The door was opened when there was a gap between flow of people in the stairwell.

Although none of the observers who descended with the evacuees directly reported the condition of congestion, it was clearly witnessed in the recorded picture at the 14th, the 25th and the 26th floor where evacuating people were stopped several times for 10 or 15 seconds due to congestion in the lower floors. It is regrettable that observer-evacuees started descending too late to encounter such cases of flow stagnation in the stairwell.

If the observed speed is used, it becomes clear that it will take at least around 13 minutes for the residents to evacuate to the ground from the 53rd story without slowing down of the people's flow. During the actual evacuation, however, flow stagnation or at least slowing down of the flow will inevitably occur. Two factors will contribute to this. First, each stairwell could hold only 40 persons per floor according to the observed density, whereas at least 200 persons are expected to evacuate from each floor through two emergency stairs. Supposing that just a half of the evacuees come to the east stairwe11, this amounts to 100 persons. Pauls $(5)$ discussed that flow capacity of stairwell decreases if flow density is exceeded 2 persons per square metre, and there is a good reason to assume this condition to happen. Secondly, during the mixing of people's flow on the landings, there may arise a standstill on either side to let the others to go forward, as happened in the observation. This also leads to a flow stagnation in the stairwel1. Therefore, it does not seern to make sense to assume total evacuation in case of emergency. It is highly probable from the present result that a standstill in the stair may appear if 3 or 4 neigbouring floors were simultaneously evacuated. From this point of view, the stair width is clearly insufficient.

There is no explicit statement in the Japanese Building Codes as to whether total evacuation is needed for highrise buildings or not. In practice, the underlying assumption seems: Fires will not occur which require total evacuation because various countermeasures are provided; secondly, all the residents of one floor could take a temporary refuge in the adjoining lobby spaces of emexgency stairs free of smoke and fire, before they are totally evacuated from the building; and thirdly, such a total evacuation that requires simultaneous use of the stairs is unlikely to happen. It is still debatable, however, if there might be cases when immediate evacuation is desirable, such as a bomb threat or post-earthquake fires.

\section{Personal Factors Affecting Emergency Preparedness}

The general knowledge of evacuation procedures or various escape facilities provided in the building deeply depends upon the length of time after their initiation of work in the building and also upon the role the subjects are supposed to play during emergency. If they were designated as members of the private fire brigade, they tended to study beforehand the procedures of the evacuation, and thus they understood the importance of repeated practice of fire evacuation. In contrast, previous experience of fire or bomb threat has had no effect on the attitude of the residents toward the necessity of evacuation practice. Although there exists a brief manual explaining the details of the 
evacuation procedures and facilities, it was distributed only once when the building was completed. Thus, the younger subjects have had no chance of reading the manual or listening to the explanation.

\section{CONCLUSION}

Result of the present observation suggests that effective procedures for selective evacuation that will cause little congestion in the emergency stairwell should be developed. Simultaneous total evacuation as it is now considered might cause more trouble than selective evacuation for the residents that need most urgent evacuating action. This is vital for Japanese highrise buildings to cope with earthquake induced multiple fires. Evacuation procedures that positively utilize such spaces as stories for machinery that are designed as areas of temporary refuge need development.

It is advisable, on the other hand, that a brief manual explaining procedures in case of emergency is repeatedly printed and distributed to all workers in the building. This will certainly assist the residents of the building to realize the importance of fire and other safety measures.

\section{ACKNOWLEDGEMEN'TS}

The authors would like to express their sincere thanks to the management staff of the building who allowed the authors to conduct observation during the evacuation practice. Thanks also go to a lot of colleagues in the Building Research Institute for their assistance to set up the equipments on the site. The work was conducted as a part of the Research Project on the Development of Design System for Building Fire Safety, financed by the Ministry of Construction.

\section{REFERENCES}

1. Jake L. Pauls and Brian K. Jones, "Building evacuation: Research methods and studies", in Fires and Human Behaviour, edited by David Canter (John Wiley and Sons, Chichester, 1980), pp.227-249.

2. Jake L. Pauls (private communication).

3. Jake L. Pauls, "Building evacuation: Research findings and recommendations", in Fires and Fuman Behaviour, edited by David Canter (John Wiley and Sons, Chichester, 1980), pp.251-275.

4. Satoshi Kose, Yoshihiro Endo and Hidetaka Uno, "Experimental determination of stair dimensions required for safety", in Proceedings of the International Conference on Building Use and Safety Technology, (National Institute of Building Sciences, Washington,D.C., 1985), pp.134-138.

5. Jake L Pauls, ibid., pp.272-274. 